\title{
Patterns of adult and youth inpatient admissions before and after the COVID-19 pandemic in a psychiatric ward: an observational study
}

Carolina Alves Rodrigues ( $\nabla$ anacarolinarodrigues@chpl.min-saude.pt )

Centro Hospitalar Psiquiátrico de Lisboa

Nuno Rodrigues

Centro Hospitalar Psiquiátrico de Lisboa

Miguel Nascimento

Centro Hospitalar Psiquiátrico de Lisboa

Joana Oliveira-Silva

Hospitais da Universidade de Coimbra

\section{Research Article}

Keywords: COVID-19, Psychiatric Department, Delivery of Health Care, Mental disorders, Patient

Readmissions

Posted Date: February 14th, 2022

DOI: https://doi.org/10.21203/rs.3.rs-1140588/v1

License: (c) (i) This work is licensed under a Creative Commons Attribution 4.0 International License.

Read Full License 


\section{Abstract}

Background: The current pandemic situation led to deep changes not only in social relationships, but also on clinical care and access to healthcare facilities. The authors aimed to understand if this context led to a different pattern of treatment of patients with severe mental illness, measured by admissions in an acute psychiatric ward.

Methods: Retrospective data collection of all patients admitted in Centro Hospitalar Psiquiátrico de Lisboa, in two different time periods: pre-COVID-19 (march 11th, 2019 to march 10th, 2020, n=1845) and COVID-19 (march 11th, 2020 to march 10th, 2021, n=1278); comparing the number of total admissions, compulsory ones, age, sex, median days of admission, median days to readmission and diagnosis at discharge. Distribution of disorders in both groups, as well as in compulsory admissions were also evaluated. The same comparisons were evaluated in the 15-25-year-old patient group.

Results: Statistical significance was found regarding total number of admissions (reduction of around $30.7 \%$ ), as well as compulsory ones (reduction of $14 \%$, although the relative frequency had increased), days of admission and distribution between admissions (with lower reductions regarding dementias, schizophrenia and affective disorders, while substance use disorders and intellectual disabilities presented reductions of over $50 \%$ ), with no differences between gender, median age, previous admissions or readmissions. Distribution between compulsory admissions did not present differences before and during COVID periods.

For patients between 15 and 25 years of age, statistical significance was found regarding total number of compulsory ones (94 versus $44, p$-value $=0.01$ ), and in all group of diagnoses (all with $p$-value $=0.001$ ).

Conclusions: While there was a general reduction in the overall number of patients admitted, in the most severe conditions (compulsory admissions and schizophrenia diagnosis) did not present such a reduction. Difficulties in social, clinical and family networks can explain the reduction of the time to readmission. Future research could show whether there is a rebound increase number of admissions in the other diagnoses.

Trial Registration: the current study was approved by the hospital's scientific and ethics committees (CCP number 0060/2021 and CES 09/2021).

\section{Background}

The spread of SARS-CoV-2, the virus that ended up causing the 2019 coronavirus disease (COVID-19) and pandemic implicated a drastic shift in our patterns of living. The COVID-19 outbreak was declared an international public health emergency on January 30, 2020 by the World Health Organization (WHO) (1). Authorities in various countries soon enforced strict measurements of social distancing, such as implementing online labour, the closing of schools and cancelation of major public events and limiting contact outside the family core. Although these had the purpose of ensuring safety and limiting the 
spread of the virus, they imposed disruption in people's lives. The unpredictability and rapidness of the spreading of the disease and its impact in daily life has been causing universal awareness, along with anxiety and distress, all of which are considered natural responses to the randomly changing circumstances (2).

According to a 2013 national study on mental health (3), mental illness affects more than $20 \%$ of the Portuguese population. The most prevalent disorders are anxiety $(16,5 \%)$ and depressive $(7,9 \%)$ disorders. The lifetime prevalence of mental disorders in the country is $42,7 \%$, which is much higher than the rest of the world (29.2\%) (4), thus being highly susceptible to severe mental health issues caused from this pandemic. The purpose of this study is to ascertain whether the main characteristics of the patients admitted in a psychiatric ward were affected during the pandemic period, and to ultimately reflect on the fragilities of a health care system which was put under extreme strain. This contemplation becomes even more relevant through the severe mental illness (SMI) optics. This concept was created to allow health care professionals to identify the most vulnerable subjects with mental disorders within the population and to aid in the planning of specific interventions. It is overall assessed through many variables, such as the duration of the illness, the number of hospital admissions, disability, safety, availability of support and aggressiveness of the patient (5).

\subsection{The psychosocial impact of quarantine and isolation}

COVID-19 required the implementation of quarantine measures as a fundamental disease control measure. In 2003, during the severe acute respiratory syndrome coronavirus 1 (SARS) pandemic, which was also successfully contained through the application of similar measures, a study showed that a substantial proportion of quarantined persons felt distressed. This was displayed by a high proportion of post-traumatic stress disorder (PTSD) and depressive symptoms manifested in this population. In the same study, the presence of these symptoms was highly correlated with the duration of the quarantine (2). There were also reports of higher likeliness of exhaustion, detachment from others, anxiety when dealing with febrile patients, irritability, insomnia, poor concentration and indecisiveness,

deteriorating work performance and reluctance to work or consideration of resignation in a sample of 838 hospital staff members, immediately after a quarantine period (6). These data should lead to the conclusion that quarantine measures, even though they remain essential to the containment of the virus, might pose as a personalized trauma for those who go through the process, with possible short and longtime effects on mental health and psychiatric admissions.

\subsection{Impact on people with pre-existing psychiatric illness}

People with pre-existing psychiatric illness might be more prone to developing infectious diseases. Cognitive decline, poor awareness level, impaired risk perception and reduced concern about hygiene might increase susceptibility to infection (7). A study on patients diagnosed with Middle Eastern Respiratory Syndrome (MERS) and individuals who came into contact with MERS patients in 2016 
concluded that besides symptoms related to MERS during isolation, inadequate supplies of food, clothes or accommodation, lack of social networking activities and financial loss, history of psychiatric illness was also an important risk factor to experiencing anxiety and anger symptoms at four to six months after release from quarantine (8).

People with mental health conditions may be substantially influenced by the emotional responses brought on by the COVID-19 pandemic, which may result in worsening of already existing symptoms or full relapses with need for hospitalization. It is important to stress that a great amount of people with psychiatric illness rely on regular outpatient visits for evaluation and prescriptions, as well as home visits. Once again, nationwide regulations on circulation and mandatory quarantine may have resulted in these visits becoming more difficult to attend to. Other studies have found a decrease in the number of admissions in psychiatric units (mainly in anxiety disorders), but were restricted to relatively short periods of time $(9,10)$.

\subsection{The consequences for people with severe mental illness}

Severe mental illness may also be characterized by an impairment in insight and decision-making capacity, which could complicate these patients' ability to adapt and adhere to the protective measures recommended to prevent infection (such as hand washing, wearing masks, social distancing or mandatory quarantine). Lower awareness to the possible consequences of the COVID-19, paired with the absence of insight to a possible relapse or aggravation of previous symptoms exposes this population to a greater risk for severe clinical outcomes $(11,12)$.

\section{Methods}

To begin to fully understand how COVID-19 may have affected mental health and help-seeking behaviours of the population in general and psychiatric patients in specific, the authors examined patterns of admissions of patients to acute psychiatric wards in a major psychiatric hospital in Lisbon, Portugal - Centro Hospitalar Psiquiátrico de Lisboa (CHPL). Two time periods were analyzed: the COVID19 period (from March $11^{\text {th }}, 2020$ to March 10 ${ }^{\text {th }}, 2021$ ) and the same time period 1 year previously (preCOVID-19 period: March $11^{\text {th }}, 2019$ to March $10^{\text {th }}, 2020$ ).

The authors searched for differences in age, gender, type of admissions (voluntary versus compulsory ones, the latter being applied, according to the Portuguese Mental Health Law (13), to patients with severe decompensated mental illness who are at risk for harmful behaviour and refusal of treatment (and therefore may be assumed as an indirect measure for severity of the disorder), time period between previous psychiatric hospitalization and current one, length of admission, readmissions (counted as new psychiatric admissions at the hospital on the 120 days upon discharge) and primary diagnosis at discharge were analyzed retrospectively from hospital records. Diagnosis were clustered and analyzed based on broader diagnostic categories available in the ICD-10 (14). 
Additionally, CHPL includes an acute psychiatric ward created towards the treatment of patients in transition from Child Psychiatry to Adult Psychiatry. Patients from 15-25 years old are committed and observed, from 15-17 years, by Child Psychiatrists, and from 18 years old upwards, by Adult Psychiatrists. Being a more fragile group of patients, in which interpersonal relationships with friends and close relatives assume a bigger role in their stability, they may also be considered as more prone to mental health issues deriving from the general lockdown and school closures. For that reason, these patients were additionally studied in separate, for the same variables (15).

\subsection{Data collection}

Upon approval from the hospital's ethical and scientific committees, the authors were given the anonymized dataset from the hospital with the variables asked. Since no patient was able to be identified, no consent form was needed or demanded.

\subsection{Statistical analysis}

The statistical analysis was performed using SPSS 26.0 (IBM, USA). Quantitative variables were tested for normality using Shapiro Wilk test. Comparisons between groups were performed using Mann-Whitney $U$. The Chi-Square Test of Independence was used to determine association between categorical variables. When more than $20 \%$ of cells have expected frequencies lower than 5 , Fisher's exact test was used. Significance level was established at 0.05 .

Two different populations in the statistical analysis were considered: the total number of patients ( $N=3123,1845$ from the pre-COVID-19 period and 1278 on the COVID-19 one) and those aged between 15 to 25 years ( $\mathrm{N}=388$ during control period and $\mathrm{N}=268$ during the COVID-19 period), which were committed to a transition clinic at work within our hospital,

The following variables were calculated: median age, prevalence of each gender, compulsory treatment, median admission period, number of patients with previous admissions and median of days since those admissions, number of patients who had readmissions (measured as another psychiatric admission in the 120 days after discharge), median days between discharge and new hospitalizations, and different clusters of diagnosis in each sample, according to the sub-chapters of the ICD-10:

- Mental disorders due to known physiological conditions (F00-09)

- Mental and behavioural disorders due to use of alcohol (F10)

- Mental and behavioural disorders due to use of other psychoactive substances (F11-19)

- Schizophrenia, schizotypal and delusional disorders (F20-29)

- Bipolar disorder (F30-31)

- Depressive disorder (F32) 
- Neurotic, stress-related and somatoform disorders (F40-48)

- Disorders of adult personality and behaviour (F60-69)

- Intellectual disabilities (F70-79)

- Others (since the number of other diagnoses were very small overall)

The main purpose of this analysis was to observe the differences between the control group and the COVID-19 period group.

Additionally, to the overall number of patients, the authors calculated the percentage reduction of admissions between the two periods, regarding the overall number and the diagnostic clusters, in order to understand if all kinds of patients presented the same variation in admissions.

Finally, regarding compulsory admissions, the frequency of each cluster of diagnosis was compared between pre- and COVID-19 periods.

\section{Results}

\subsection{Characteristics of all admitted patients}

The final analytic cohort for the sample of hospitalized patients included 1845 patients in the pre-COVID19 period, and 1278 on the COVID period. Table 1 reports descriptive characteristics of the overall sample, such as median age, gender, prevalence of compulsory treatment, admission period, frequency of patients with previous admissions (and median of days since then) and frequency of readmissions in the following 120 days (and median days to these readmissions).

Total number of admissions was lower during the COVID-19 period, with less 567 hospitalizations during the COVID-19 period (a reduction of $30.7 \%$ of psychiatric admissions during this period of time). The median age of the patients was 43 years old in the control period and 45 years old during the COVID-19 year.

Between the two groups, statistical differences were found regarding the age of patients (with older patients in the COVID-19 period), duration of admission (higher in the COVID-19 period), previous admissions (with more than half of the patients on the COVID-19 period having had them) and frequency of compulsory admissions (with around a third of total patients being against the patient's will in the COVID-19 period). No difference was found regarding gender, days since the last admission, frequency of readmissions or the number of days towards these readmissions. Multiple comparisons only found relevance for the duration of admissions and number of compulsory ones.

\section{Table 1}


Characteristics of the sample of hospitalized patients. Y, year, IQR, interquartile range; $d$, days

\begin{tabular}{|llll|}
\hline & $\begin{array}{l}\text { Pre-COVID-19 } \\
\text { period } \\
(\mathrm{n}=1845)\end{array}$ & $\begin{array}{l}\text { COVID-19 } \\
\text { period } \\
(\mathrm{n}=1278)\end{array}$ & $\begin{array}{l}\text { p } \\
\text { value }\end{array}$ \\
\hline Age, $y$, median (IQR) & $43(28-56.5)$ & $45(28-59)$ & 0.026 \\
\hline Sex, female, $\mathrm{n}(\%)$ & $862(46.7)$ & $630(49.3)$ & 0.157 \\
\hline Compulsory, $\mathrm{n}(\%)$ & $494(26.8)$ & $425(33.3)$ & $<0.001$ \\
\hline Admission duration, d, median & 15 & 16 & $<0.001$ \\
\hline Previous admissions, $\mathrm{n}$ (\%) & $905(49,1)$ & $674(52.7)$ & $\mathbf{0 . 0 4 3}$ \\
\hline Time from last admission, d, median & 261 & 315 & 0.181 \\
\hline $\begin{array}{l}\text { Psychiatric admissions in the following 120days, } \mathrm{n} \\
\text { (\%) }\end{array}$ & $299(16.2)$ & $218(17.1)$ & 0.529 \\
\hline $\begin{array}{l}\text { Psychiatric admissions in the following 120days, } \mathrm{d}, \\
\text { median }\end{array}$ & 29 & 25 & 0.056 \\
\hline
\end{tabular}

\subsection{Diagnostic clusters of hospitalized patients}

As the Table 2 shows, the majority of hospitalizations was due to "Schizophrenia, schizotypal and delusional disorders" in both groups, corresponding to $28.6 \%$ of all admissions during the control period, with an increase to $35.5 \%$ during the COVID-19 period. "Bipolar disorder" (F31) and "Depressive disorder" (F32) were next as most diagnosed in both years. It is important to notice, though, that during the control period there were 258 admissions due to "Mental and behavioural disorders due to the use of alcohol" (F10), while during the COVID-19 period, these disorders amounted only to 76 hospitalizations. As for "Neurotic, stress-related and somatoform disorders" (F40-48), "Disorders of adult personality and behaviour" (F60-69) and Intellectual disabilities (F70-79), all presented a large decrease in hospitalizations during the COVID-19 period. Statistical difference was found regarding the distribution of diagnosis between the two groups.

\section{Table 2}

\section{Frequency of diagnosis of the patients admitted between the 2 groups}




\begin{tabular}{|c|c|c|c|}
\hline Diagnosis, $\mathrm{n}$ (column \%) & $\begin{array}{l}\text { Pre-COVID-19 } \\
\text { period } \\
(n=1845)\end{array}$ & $\begin{array}{l}\text { COVID-19 } \\
\text { period } \\
(n=1278)\end{array}$ & $\begin{array}{l}\mathbf{p} \\
\text { value }\end{array}$ \\
\hline $\begin{array}{l}\text { Mental disorders due to known physiological conditions } \\
\text { (F00-F09) }\end{array}$ & $76(4.1)$ & $68(5.3)$ & $<0.001$ \\
\hline $\begin{array}{l}\text { Mental and behavioural disorders due to use of alcohol } \\
\text { (F10) }\end{array}$ & $258(14)$ & $76(5.9)$ & \\
\hline $\begin{array}{l}\text { Mental and behavioural disorders due to use of other } \\
\text { psychoactive substances (F11-19) }\end{array}$ & $101(5.5)$ & $49(3.8)$ & \\
\hline $\begin{array}{l}\text { Schizophrenia, schizotypal and delusional disorders (F20- } \\
\text { 29) }\end{array}$ & $528(28.6)$ & $454(35.5)$ & \\
\hline Bipolar disorder (F31) & $313(17)$ & $228(17.8)$ & \\
\hline Depressive disorder (F32) & $307(16.6)$ & $260(20.3)$ & \\
\hline Neurotic, stress-related and somatoform disorders (F40-48) & $65(3.5)$ & $35(2.7)$ & \\
\hline Disorders of adult personality and behaviour (F60-69) & $105(5.7)$ & $53(4.1)$ & \\
\hline Intellectual disabilities (F70-79) & $72(3.9)$ & $22(1.7)$ & \\
\hline Others & $20(1.1)$ & $33(2.6)$ & \\
\hline
\end{tabular}

Figure 1 shows the discrepancy of admissions between the two groups, regarding their diagnosis.

According to the data gathered, there was a reduction of $30.73 \%$ of the total admissions between the two groups. However, this reduction was higher in the patients with substance use disorder, neurotic, and somatoform disorders, personality disorders and intellectual handicap, whereas dementias, affective disorders and schizophrenia, schizotypal and delusional disorders presented a lower reduction of admissions compared to the whole group of patients (as presented in Figure 2).

\subsection{Association between diagnostic cluster and compulsory admissions}

Regarding compulsory admissions, even though their relative frequency increased in the COVID-19 group (that is, even though there was a reduction in $14 \%$ in the overall number of compulsory admissions, they represented an increase of around $7 \%$ compared to the total admissions), the distributions of diagnosis was not different between the two groups ( $p$-value $=0.157$ ), with "Schizophrenia, schizotypal and delusional disorders" and "Bipolar disorders" corresponding for around three-quarters of the compulsory admissions. Table 3 and Figure 3 present these comparisons.

\section{Table 3}


Frequency of diagnosis of the patients compulsorily admitted between the 2 groups

\begin{tabular}{|c|c|c|c|}
\hline Diagnosis, $\mathrm{n}$ (column \%) & $\begin{array}{l}\text { Pre-COVID-19 } \\
\text { period } \\
(n=1845)\end{array}$ & $\begin{array}{l}\text { COVID-19 } \\
\text { period } \\
(n=1278)\end{array}$ & $\begin{array}{l}\mathrm{p} \\
\text { value }\end{array}$ \\
\hline $\begin{array}{l}\text { Mental disorders due to known physiological conditions } \\
\text { (F00-F09) }\end{array}$ & $15(3)$ & $16(3.8)$ & 0.157 \\
\hline Mental and behavioural disorders due to use of alcohol (F10) & $13(2.6)$ & $16(3.8)$ & \\
\hline $\begin{array}{l}\text { Mental and behavioural disorders due to use of other } \\
\text { psychoactive substances (F11-19) }\end{array}$ & $45(9.1)$ & $22(5.2)$ & \\
\hline Schizophrenia, schizotypal and delusional disorders (F20-29) & $238(48.2)$ & $224(52.7)$ & \\
\hline Bipolar disorder (F31) & $115(23.3)$ & $106(24.9)$ & \\
\hline Depressive disorder (F32) & $19(3.8)$ & $12(2.8)$ & \\
\hline Neurotic, stress-related and somatoform disorders (F40-48) & $6(1.2)$ & $7(1.6)$ & \\
\hline Disorders of adult personality and behaviour (F60-69) & $25(5.1)$ & $12(2.8)$ & \\
\hline Intellectual disabilities (F70-79) & $12(2.4)$ & $5(1.2)$ & \\
\hline Others & $6(1.2)$ & $5(1.2)$ & \\
\hline
\end{tabular}

\subsection{Characteristics of hospitalized patients from 15-25 years}

Regarding the transition to adulthood group of patients, as shown in Table 4, the final analytic cohort for the sample of hospitalized patients between 15-25 years old was 388 hospitalizations during the PreCOVID-19 period and 268 hospitalizations during the COVID-19 period. The total number of admissions was significantly lower during the COVID-19 period, with less 120 hospitalizations (a decrease of 30,9\%). The median age of the patients was 19 years old in the control period and only 18 years old during the COVID-19 period.

Prevalence of compulsory hospitalization in patients from 15-25 years was much lower than in the 25+ years sample, with 94 compulsory admissions during the first period and only 44 during the pandemic year. There were no significant differences between groups regarding duration of these admissions, number of previous admissions or readmission rates. Multiple comparison statistics revealed no difference on any variable between these two groups.

\section{Table 4}


Characteristics of hospitalized patients from 15-25 years. Y, year, d, days

\begin{tabular}{|llll|}
\hline & $\begin{array}{l}\text { Pre-COVID-19 } \\
\text { period } \\
(\mathrm{n}=388)\end{array}$ & $\begin{array}{l}\text { COVID-19 } \\
\text { period } \\
(\mathrm{n}=268)\end{array}$ & $\begin{array}{l}\text { p } \\
\text { value }\end{array}$ \\
\hline Age, $\mathrm{y}$, median (IQR) & $19(17-22)$ & $18(17-22)$ & 0.099 \\
\hline Sex, female, $\mathrm{n}(\%)$ & $193(49.7)$ & $142(53)$ & 0.231 \\
\hline Compulsory, $\mathrm{n}(\%)$ & $94(24.2)$ & $44(16.4)$ & 0.010 \\
\hline Admission duration, d, median & 13 & 13 & 0.747 \\
\hline Previous admissions, $\mathrm{n}(\%)$ & 119 & 102 & 0.05 \\
\hline Time from last admission, d, median & 100 & 171 & 0.036 \\
\hline $\begin{array}{l}\text { Psychiatric admissions in the following 120 days, } \mathrm{n} \\
\text { (\%) }\end{array}$ & 64 & 42 & 0.778 \\
\hline $\begin{array}{l}\text { Psychiatric admissions in the following 120 days, } \mathrm{d}, \\
\text { median }\end{array}$ & 24 & 17.50 & 0.452 \\
\hline
\end{tabular}

\subsection{Diagnostic clusters of hospitalized patients between 15- 25 years}

In the sample shown in Table 5, the majority of hospitalizations was due to "Depressive Disorder" (F32) in both groups, totalizing $30.9 \%$ of all admissions during the pre-COVID-19 period, with an increase to $45.5 \%$ during the COVID-19 period. "Schizophrenia, schizotypal and delusional disorders" (F20-29) amounted to $24.5 \%$ hospitalizations during the control period and only $17.5 \%$ during the COVID-19 period. During the pre-pandemic period there were 8 hospitalizations due to "Mental and behavioural disorders due to the use of alcohol" (F10), with less than half (3) during the COVID-19 period. "Intellectual disabilities" (F7079) had the biggest downfall during the COVID-19 period, with a decrease of $73.3 \%$ of hospitalizations.

\section{Table 5}

Diagnostic clusters of hospitalized patients from 15-25 years 


\begin{tabular}{|llll|}
\hline Diagnosis, $n$ (column\%) & $\begin{array}{l}\text { Pre-COVID-19 } \\
\text { period } \\
(\mathrm{n}=388)\end{array}$ & $\begin{array}{l}\text { COVID-19 } \\
\text { period } \\
(\mathrm{n}=268)\end{array}$ & $\begin{array}{l}\text { p } \\
\text { value }\end{array}$ \\
\hline $\begin{array}{l}\text { Mental disorders due to known physiological conditions } \\
\text { (F00-F09) }\end{array}$ & $0(0)$ & $1(0.4)$ & 0.001 \\
\hline Mental and behavioural disorders due to use of alcohol (F10) & $8(2.1)$ & $3(1.1)$ \\
\hline $\begin{array}{l}\text { Mental and behavioural disorders due to use of other } \\
\text { psychoactive substances (F11-19) }\end{array}$ & $28(7.2)$ & $14(5.2)$ \\
\hline $\begin{array}{l}\text { Schizophrenia, schizotypal and delusional disorders (F20-29) } \\
\text { Bipolar disorder (F31) }\end{array}$ & $95(24.5)$ & $47(17.5)$ \\
\hline Depressive disorder (F32) & $44(11.3)$ & $29(10.8)$ \\
\hline Neurotic, stress-related and somatoform disorders (F40-48) & $120(30.9)$ & $122(45.5)$ \\
\hline Disorders of adult personality and behaviour (F60-69) & $33(8.5)$ & $7(2.6)$ \\
\hline Intellectual disabilities (F70-79) & $30(7.7)$ & $8(3.0)$ \\
\hline Others & $9(2.3)$ & $15(5.6)$ \\
\hline
\end{tabular}

\section{Discussion}

The main focus of this study was to evaluate the differences between the characteristics of both samples during the control period - March 11, 2019 to March 10, 2020 - and during the COVID-19 period - March 11, 2020 to March 11, 2021 - using data from all acute psychiatric wards in CHPL. During the latter period of time, Portugal was put under rigorous restrictions which included the cessation of all unemergent activity, such as medical appointments, therapeutic groups and occupational therapy programs.

This study allows an understanding on psychiatric hospitalizations in one of the largest psychiatric hospitals in Portugal, considering a broad time frame (1 year for each group, therefore encompassing not only the first lockdown, but also the months right after these measures).

There was a decrease in total hospitalizations during the COVID-19 period (30.7\% less admissions in patients above 25 years old and $30.9 \%$ in patients between 15 and 25 years of age). This reduction was similar in other studies (16). We could hypothesize that this was due to a reduction of the number of patients visiting the emergency units, which was also described in other studies (17-20). However, it could be said that the occupation of hospitals and its human resources, which were almost fully allocated to dealing with the pandemic, and the switch to online or telemedicine, may have, in some way, disrupted the referral system previously put in place for psychiatric patients. 
Despite the fact that the number of compulsory admissions was lower during the COVID-19 period in both samples, this reduction was lower than the general reduction of admissions ( $14 \%$ versus $30.7 \%)$. This represents an increase in the relative proportion of compulsory admissions during the same period (26.8 versus $33.3 \%$ ). There was also an association between the diagnosis of "Schizophrenia, schizotypal and delusional disorders" (F20-29) and treatment under the Portuguese Mental Health Law $(p<0.001)$. This may suggest that less severe patients avoided emergency rooms altogether (possibly due to a perception of higher risk of virus transmission), but also that the patients that were brought to the emergency department presented more severe symptoms, with lack of insight regarding their condition. Other studies presented similar results, although there doesn't seem to be a role of gender in the differences of admissions in these periods $(21,22)$.

In both periods, there seems to be no difference between number of previous admissions or rates of readmissions (after multiple comparisons), but the overall number of patients were admitted for longer periods of time. This suggests that either patients presented worse symptomatology or that there were poorer conditions to provide a safe and multidisciplinary discharge plan focused on relapse prevention. It is not to exclude the fact that there might be a bias in these conclusions, since the biggest reduction of admissions were observed in patients with usually milder symptoms. This was also in line with other studies $(9,16,17)$. Looking at the diagnosis at discharge, the most severe neuropsychiatric disorders (dementia, schizophrenia, bipolar disorder and depression with suicidal risk) presented a lower reduction of admissions when compared to the overall average, which could explain the need for longer admissions.

Regarding diagnostic clusters, it is important to stress the massive decrease in hospitalizations due to "Mental and behavioural disorders due to use of alcohol" (F10) during the COVID-19 period. This could be explained by the fact that admissions for alcohol dependence are mainly programmed and therefore reduced during the pandemic.

The most prevalent diagnostic cluster in the sample of 15-25 year old patients was "Depressive disorders" (F32), with an actual increase in the frequency of this diagnosis, both in absolute number but also in relative frequency (from $30.9 \%$ to $45.5 \%$ of the admissions during the pandemic). This may hint at this population's higher vulnerability to stress and anxiety, paired with less coping skills to handle measures which were implemented during the pandemic (such as school closures or not being able to spend time with their friends) (23). However, because individual patient files' weren't accessed, the authors cannot understand if these admissions due to depressive symptoms were related to any kind of COVID-related stressors, like other studies suggest $(10,23)$.

Although our sample represented a total of 1845 and 1278 hospitalizations during the control period and the COVID-19 period, respectively, the variety of diagnosis forced us to cluster most of them in certain diagnostic groups. This may have worked as a limitation to our study as, for example, within the "Mental disorder due to use of other psychoactive substances", a lot of the patients were diagnosed with 
polysubstance use, which prevents us from studying which psychoactive substance had the most increase in usage.

This study allowed an evaluation of the hospital's response during the pandemic. The optimization of its approach to SMI patients and the prediction of future challenges are ahead. It is possible that an increase in future diagnosis of affective and anxious/neurotic disorders, suicide attempts and substance use disorders is due. Further studies concerning the majority of 2021 could be able to help in the understanding of the long-term effects of this pandemic on severe mental health patients, as well at the efficacy of the institution's response, in line with the work of Hawryluck L et al in 2003 (2). However, since there's no direct access to patients' files, the authors will never be able to understand if these admissions are COVID related.

\section{Conclusions}

The COVID-19 pandemic has undoubtedly imposed a challenging crisis in the previous prevention-andintervention health care model. It becomes clear there is a need for rapid identification of at-risk groups for psychological and psychiatric complications, which requires proper screening methods, in-time referral and the promotion of early and targeted intervention.

The main take away from this study could be that although there was a reduction in the total of psychiatric admissions, in regards to SMI patients with acute symptomatology, healthcare was still available, proving the referral systems put in place were actually effective.

Further research is needed to recognize in which way has the COVID-19 pandemic affected patterns of psychiatric hospital admissions. The authors believe that some consequences might only be acknowledged through the study of this population of patients in the next few years.

\section{Abbreviations}

CHPL - Centro Hospitalar Psiquiátrico de Lisboa

COVID-19 - 2019 Coronavirus Disease

ICD-10 - International Classification of Diseases, $10^{\text {th }}$ Edition (World Health Organization)

SARS-CoV-2 - Severe acute respiratory syndrome coronavirus 2

\section{Declarations}

\section{Ethics approval and consent to participate}

All methods were carried out in accordance with the relevant guidelines and regulations the current study was approved by the hospital's Scientific and Ethics committees (CCP number 0060/2021 and CES 
09/2021). The data given was already anonymized, which made it impossible to contact or identify any of the patients. For this reason, the Ethics Committees, which is designated Comissão de Ética para a Saúde of Centro Hospitalar Psiquiátrico de Lisboa, also waived the need for informed consent.

\section{Consent for publication}

Not applicable.

\section{Availability of data and materials}

The data supporting the findings of this study are available from Centro Hospitalar Psiquiátrico de Lisboa, but restrictions apply to the availability of these data, which were used under license for the purpose of the study, and so are not publicly available. However, these data are available to the authors and should be consulted under reasonable request and permission of Centro Hospitalar Psiquiátrico de Lisboa. This access should be previously requested via e-mail to the corresponding author.

\section{Competing interests}

The authors declare that they have no competing interests.

\section{Funding}

No funding was provided for this study.

\section{Authors' contributions}

JOS statistically analyzed the available data. CAR, NR and MN all contributed to the remaining research and writing of the article. All authors read and approved the final manuscript.

\section{Acknowledgements}

The authors acknowledge CHPL for providing the data already anonymized, in line with the current data protection laws.

\section{References}

1. Dubey S, Biswas P, Ghosh R, Chatterjee S, Dubey MJ, Chatterjee S, et al. Psychosocial impact of COVID-19. Diabetes Metab Syndr Clin Res Rev [Internet]. 2020 Sep;14(5):779-88. Available from: 
https://linkinghub.elsevier.com/retrieve/pii/S1871402120301545

2. Hawryluck L, Gold WL, Robinson S, Pogorski S, Galea S, Styra R. SARS control and psychological effects of quarantine, Toronto, Canada.Emerg Infect Dis. 2004;10(7):1206-12.

3. Almeida J, Xavier M, Cardoso G, Pereira M, Gusmão R, Corrêa B, et al. Estudo Epidemiológico Nacional de Saúde Mental - 1. ${ }^{\circ}$ Relatório. 2013. 60 p.

4. Steel Z, Marnane C, Iranpour C, Chey T, Jackson JW, Patel V, et al.The global prevalence of common mental disorders: A systematic review and meta-analysis 1980-2013.Int J Epidemiol. 2014;43(2):476-93.

5. Martínez-Martínez C, Richart-Martínez M, Ramos-Pichardo JD.Operational Definition of Serious Mental IIIness: Heterogeneity in a Review of the Research on Quality-of-Life Interventions. J Am Psychiatr Nurses Assoc. 2020;26(3):229-44.

6. Bai YM, Lin CC, Lin CY, Chen JY, Chue CM, Chou P. Survey of stress reactions among health care workers involved with the SARS outbreak. Psychiatr Serv. 2004;55(9):1055-7.

7. Yao H, Chen JH, Xu YF. Patients with mental health disorders in the COVID-19 epidemic. The Lancet Psychiatry. 2020;7(4):e21.

8. Jeong H, Yim HW, Song Y-J, Ki M, Min J-A, Cho J, et al. Mental health status of people isolated due to Middle East Respiratory Syndrome. Epidemiol Health [Internet]. 2016 Nov 5;38:e2016048. Available from: https://www.ncbi.nlm.nih.gov/pmc/articles/PMC5177805/

9. Gómez-Ramiro M, Fico G, Anmella G, Vázquez M, Sagué-Vilavella M, Hidalgo-Mazzei D, et al. Changing trends in psychiatric emergency service admissions during the COVID-19 outbreak: Report from a worldwide epicentre. J Affect Disord [Internet]. 2021 Mar;282(January):26-32. Available from: https://linkinghub.elsevier.com/retrieve/pii/S0165032720331475

10. Boldrini T, Girardi P, Clerici M, Conca A, Creati C, Di Cicilia G, et al.Consequences of the COVID-19 pandemic on admissions to general hospital psychiatric wards in Italy: Reduced psychiatric hospitalizations and increased suicidality. Prog Neuro-Psychopharmacology Biol Psychiatry [Internet]. 2021 Aug;110(January):110304. Available from: https://linkinghub.elsevier.com/retrieve/pii/S0278584621000634

11. Li W, Yang Y, Liu ZH, Zhao YJ, Zhang Q, Zhang L, et al. Progression of mental health services during the COVID-19 outbreak in China. Int J Biol Sci. 2020;16(10):1732-8.

12. Lee SW, Yang JM, Moon SY, Yoo IK, Ha EK, Kim SY, et al. Association between mental illness and COVID-19 susceptibility and clinical outcomes in South Korea: a nationwide cohort study. The Lancet Psychiatry [Internet]. 2020 Dec;7(12):1025-31. Available from: https://linkinghub.elsevier.com/retrieve/pii/S2215036620304211

13. Assembleia da República. Lei n. ${ }^{\circ}$ 36/98, de 24 de Julho - Lei de saúde mental [Internet].1998 [cited 2021 Nov 11]. p. 1-9. Available from: https://www.pgdlisboa.pt/leis/lei_mostra_articulado.php? nid=276\&tabela=leis\&so_miolo=

14. Organization(WHO) WH. The ICD-10 classification of mental and behavioural disorders [Internet]. Vol. 33, World Health Organization. Genève, Switzerland: World Health Organization; 1993. 26 p. Available 
from: http://www.ncbi.nlm.nih.gov/pubmed/21793458

15. Krass P, Zimbrick-Rogers C, Iheagwara C, Ford CA, Calderoni M. COVID-19 Outbreak Among Adolescents at an Inpatient Behavioral Health Hospital. J Adolesc Heal [Internet]. 2020 Oct;67(4):612-4. Available from: https://linkinghub.elsevier.com/retrieve/pii/S1054139X20304067

16. Fasshauer JM, Bollmann A, Hohenstein S, Hindricks G, Meier-Hellmann A, Kuhlen R, et al. Emergency hospital admissions for psychiatric disorders in a German-wide hospital network during the COVID19 outbreak. Soc Psychiatry Psychiatr Epidemiol [Internet]. 2021;56(8):1469-75. Available from: https://doi.org/10.1007/s00127-021-02091-z

17. Ambrosetti J, Macheret L, Folliet A, Wullschleger A, Amerio A, Aguglia A, et al. Impact of the COVID-19 pandemic on psychiatric admissions to a large swiss emergency department: An observational study. Int J Environ Res Public Health. 2021;18(3):1-10.

18. Carpiniello B, Tusconi M, Zanalda E, Di Sciascio G, Di Giannantonio M, Di Giannantonio M, et al. Psychiatry during the Covid-19 pandemic: a survey on mental health departments in Italy. BMC Psychiatry. 2020;20(1):1-12.

19. Gonçalves-Pinho M, Mota P, Ribeiro J, Macedo S, Freitas A. The Impact of COVID-19 Pandemic on Psychiatric Emergency Department Visits - A Descriptive Study. Psychiatr Q. 2021;92(2):621-31.

20. Lucero AD, Lee A, Hyun J, Lee C, Kahwaji C, Miller G, et al. Underutilization of the emergency department during the covid-19 pandemic. West J Emerg Med. 2020;21(6):15-23.

21. Clerici M, Durbano F, Spinogatti F, Vita A, De Girolamo G, Micciolo R. Psychiatric hospitalization rates in Italy before and during COVID-19: Did they change? An analysis of register data. Ir J Psychol Med. 2020;37(4):283-90.

22. Davies M, Hogarth L. The effect of COVID-19 lockdown on psychiatric admissions: role of gender. BJPsych Open. 2021;7(4):1-7.

23. Reece L, Sams DP. The impact of COVID-19 on adolescent psychiatric inpatient admissions. Clin Child Psychol Psychiatry. 2021;0(0):1-10.

\section{Figures}




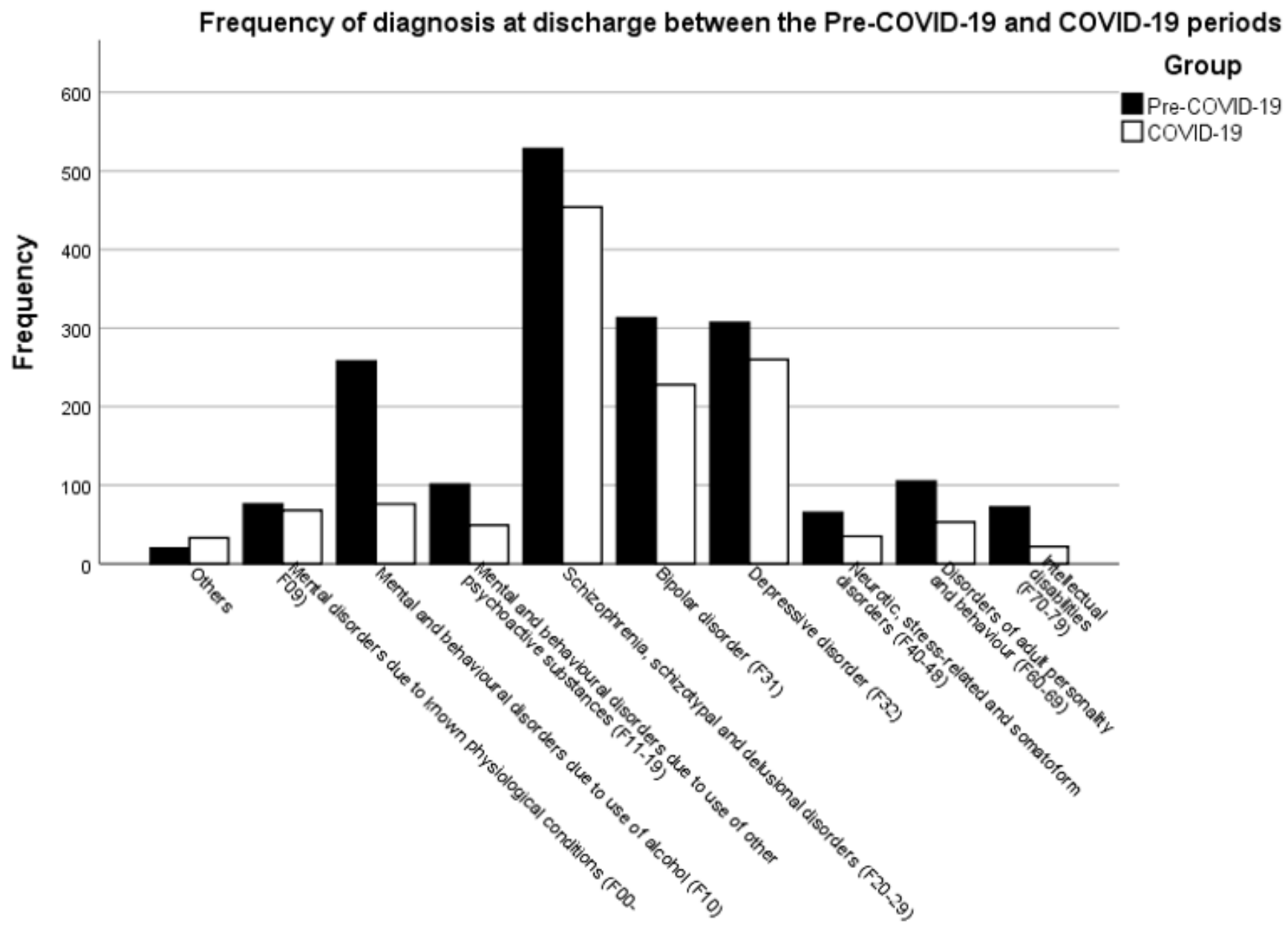

Diagnosis

Figure 1

variance of admissions in the two groups, regarding their diagnosis. 


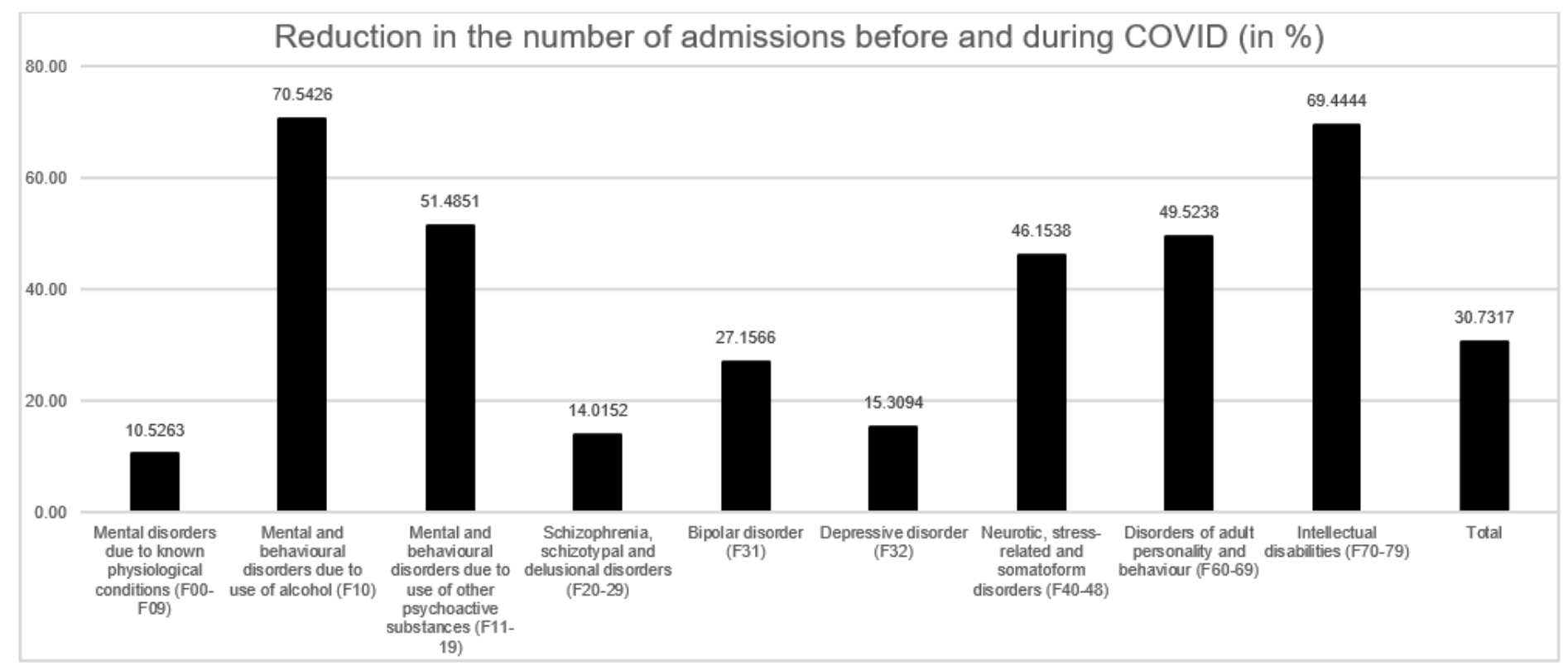

Figure 2

Reduction of admissions between the Pre-COVID-19 and COVID-19 groups, in percentage. Straight line represents the value of the reduction of the overall number of admissions

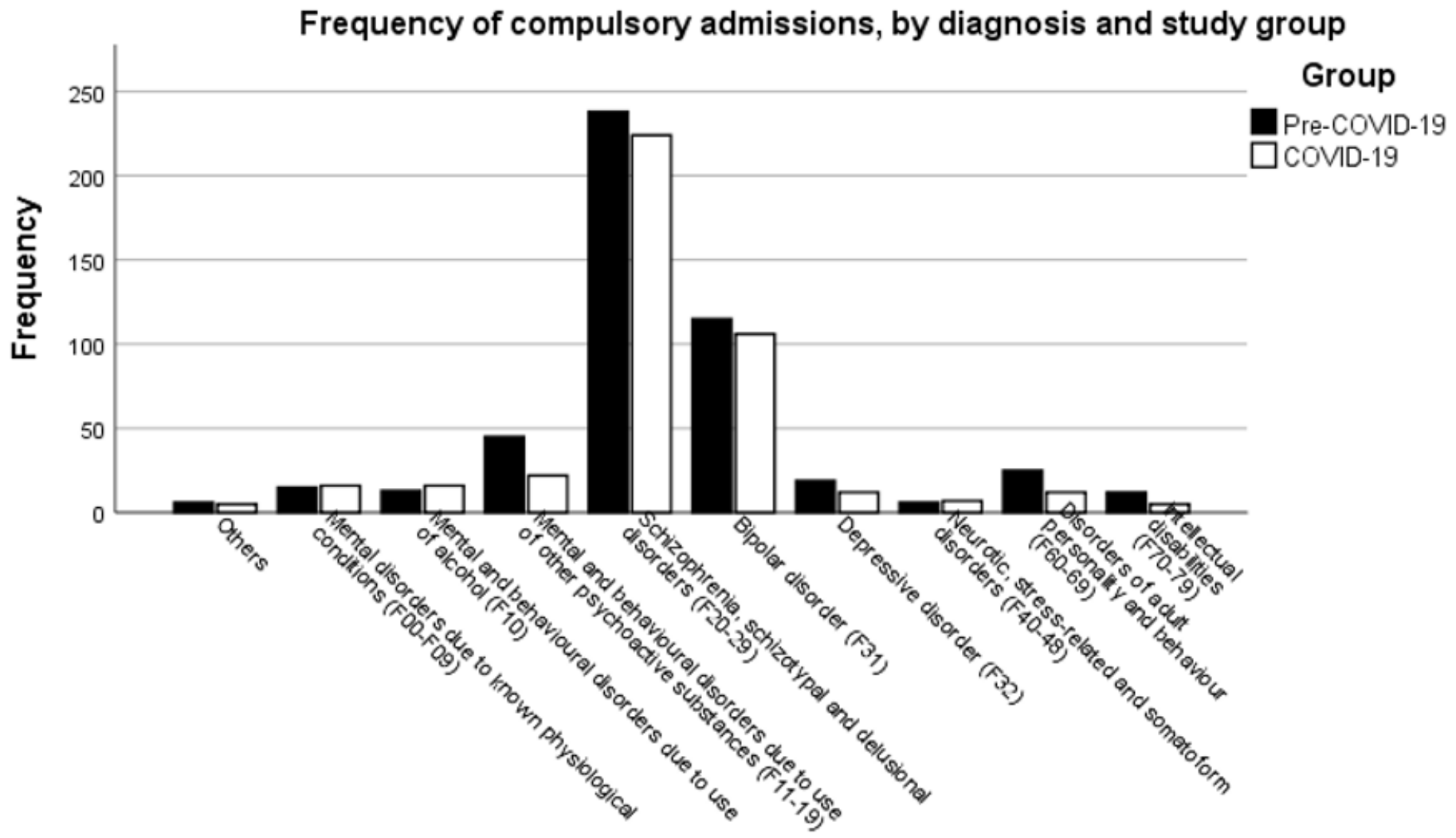


Figure 3

Frequency of compulsory admissions between pre-COVID-19 and COVID-19 groups, according to their diagnosis. 